\title{
AS AUDIÊNCIAS PÚBLICAS E OS AMICI CURIAE INFLUENCIAM AS DECISÕES DOS MINISTROS DO SUPREMO TRIBUNAL FEDERAL? E POR QUE ISSO DEVE(RIA) IMPORTAR?
}

\section{DO THE PUBLIC HEARINGS AND THE AMICI CURIAE INFLUENCE THE DECISIONS TAKEN BY THE BRAZILIAN SUPREME COURT? AND WHY IT SHOULD MATTER?}

\author{
Miguel Gualano Godoy*
}

\begin{abstract}
RESUMO: este trabalho busca fazer uma análise normativa, empírica e crítica sobre a forma como o Supremo Tribunal Federal tem se aberto à sociedade por meio da admissão de amici curiae e da realização de audiências públicas. Importa aqui investigar os passos dados e os instrumentos utilizados pelo Supremo Tribunal Federal para abrir-se ao diálogo com os demais Poderes, instituições e com o próprio povo (análise normativa), verificar se a utilização desses instrumentos realmente influenciam as decisões dos ministros do Supremo Tribunal Federal (análise empírica) e, por fim, avaliar criticamente os resultados obtidos (análise crítica).
\end{abstract}

PALAVRAS-CHAVE: Supremo Tribunal Federal. Audiência pública. Amicus Curiae.

ABSTRACT: This paper seeks to make a normative, empirical and critical analysis on how the Brazilian Supreme Court has been opening to society through amici curiae and public hearings. The goal here is to investigate the steps taken and the tools used by the Brazilian Supreme Court to be open to a dialogue with other branches, institutions and people (normative analysis); verify if the use of these tools have an effect on Justices' decisions (empirical analysis) and, finally, evaluate critically the results obtained (critical analysis).

KEYWORDS: Brazilian Supreme Court. Public hearings. Amicus Curiae.

\section{INTRODUÇÃO}

O presente artigo busca analisar criticamente a forma como o Supremo Tribunal Federal tem se utilizado da realização de audiências públicas e da admissão de amici curiae (quando também aceitos conjuntamente com as audiências públicas) para promover sua abertura à sociedade. Tal análise é baseada (i) no estudo do primeiro caso em que o STF abriu-se à participação de terceiros por meio de audiência pública e amici curiae, (ii) na verificação empírica da influência da realização de audiências públicas e da intervenção de amici curiae (quando também aceitos conjuntamente com as audiências públicas) nas decisões dos ministros do Supremo

\footnotetext{
* Doutor e Mestre em Direito Constitucional pela Universidade Federal do Paraná (UFPR). Realizou estudos e pesquisas na Harvard Law School. Pesquisador visitante na Faculdade de Direito da Universidade de Buenos Aires (UBA). Pesquisador do Núcleo Constitucionalismo e Democracia: filosofia e dogmática constitucional contemporâneas da Faculdade de Direito da UFPR, Brasil. Assessor de ministro do Supremo Tribunal Federal (ministro Luiz Edson Fachin). E-mail: miguelggodoy@hotmail.com
} 
Tribunal Federal e (iii) no exame crítico-propositivo do uso que o Supremo Tribunal Federal tem feito desses instrumentos.

O estudo do primeiro caso em que o Supremo Tribunal Federal abriu-se à participação de terceiros mediante a realização de audiência pública e admissão de amici curiae mostra os limites e as possibilidades de uma atuação da Corte que, mesmo diante de sua dificuldade contramajoritária, tenta e pode - e deve, em uma análise normativa - atuar de forma mais democrática, dialógica, de modo a possibilitar e ampliar a participação popular nos processos de discussão e decisão.

A verificação sobre como o Supremo Tribunal Federal tem se valido, desde então, da realização de audiências públicas e da admissão de amici curiae para tomar suas decisões, bem como se tais instrumentos influenciam, de fato, as decisões dos ministros do STF, deu-se por meio de pesquisa empírica com a definição da (i) análise de casos, (ii) metodologia de análise e (iii) conclusão a partir dos resultados obtidos.

A partir dos resultados obtidos com o levantamento empírico faz-se uma análise crítica e propositiva sobre a utilização desses instrumentos (realização de audiências públicas e admissão de amici curiae) pelo Supremo Tribunal Federal, fundada na teoria constitucional democráticodeliberativa contemporânea, notadamente a de Roberto Gargarella, Conrado Hübner Mendes e José Rodrigo Rodriguez.

\section{O SUPREMO TRIBUNAL FEDERAL E A SUA UTILIZAÇÃO DE AUDIÊNCIAS PÚBLICAS E ADMISSÃO DE AMICI CURIAE COMO INSTRUMENTOS PARA SUA ABERTURA À SOCIEDADE: O JULGAMENTO DA (IN)CONSTITUCIONALIDADE DA LEI DE BIOSSEGURANÇA COMO PRIMEIRA EXPERIÊNCIA}

A primeira vez que o Supremo Tribunal Federal abriu-se por meio de audiência pública à participação de terceiros não integrantes de uma Ação Direta de Inconstitucionalidade ocorreu em 2007, durante o julgamento da Ação Direta de Inconstitucionalidade (ADI) $3.510^{1}$, proposta pelo procurador-geral da República, que tratava da constitucionalidade do art. $5^{\circ}$ da Lei n. ${ }^{\circ}$ 11.105/2005 (Lei de Biossegurança). O mencionado artigo previu a utilização, para fins de pesquisa e terapia, de células-tronco obtidas de embriões humanos produzidos por fertilização in vitro e não utilizados no respectivo procedimento ${ }^{2}$.

\footnotetext{
${ }^{1}$ ADI 3.510/DF. Rel. Min. Carlos Ayres Brito. Julg. 29/05/2008.

${ }^{2}$ Art. $5^{\circ}$ É permitida, para fins de pesquisa e terapia, a utilização de células-tronco embrionárias obtidas de embriões humanos produzidos por fertilização in vitro e não utilizados no respectivo procedimento, atendidas as seguintes condições:
} 
A controvérsia sobre a utilização de células-tronco de embriões residiu sobre quando se iniciaria a vida e, assim, a partir de qual momento deveria incidir a proteção jurídica sobre o nascituro. A Procuradoria-Geral da República, em sua petição inicial, defendeu a tese de que o início da vida se daria no momento da fecundação e que, portanto, a utilização de células-tronco de embriões consistiria em um atentado à vida. Para corroborar sua tese, a Procuradoria-Geral da República anexou pareceres de cientistas e pediu então a realização de audiência pública, apresentando, desde logo, o seu rol de especialistas a serem ouvidos.

O pedido foi acatado pelo ministro relator Carlos Ayres Brito, sob a justificativa de que a audiência pública, “além de subsidiar os Ministros deste Supremo Tribunal Federal, também possibilitará uma maior participação da sociedade civil no enfrentamento da controvérsia constitucional, o que certamente legitimará ainda mais a decisão a ser tomada pelo Plenário desta nossa colenda Corte”3.

Houve sete pedidos de ingresso na ação na condição de amicus curiae. No entanto, apenas cinco pedidos foram deferidos, sem que fossem justificados na decisão do relator os motivos da aceitação ou rejeição dos pedidos. Apenas no relatório da ação o ministro relator Carlos Ayres Brito esclareceu que admitiu os amici curiae a partir da representatividade nacional dos requerentes.

Os amigos da corte tiveram papel ativo durante o trâmite do processo, juntando pareceres, notícias, estudos científicos e fazendo sustentações orais nas audiências públicas e logo antes do julgamento em plenário. Paralelamente à participação dos amici curiae, também houve a manifestação de entidades e pessoas que não requereram formalmente seu ingresso na ação, mas solicitaram a juntada de documentos para manifestar seu apoio a uma das duas posições.

A ausência de regulamentação para a realização de audiência pública no âmbito do Supremo Tribunal Federal fez com que o ministro relator Carlos Ayres Britto adotasse o Regimento Interno da Câmara dos Deputados como parâmetro. A audiência então ocorreu em dois turnos

I - sejam embriões inviáveis; ou

II - sejam embriões congelados há 3 (três) anos ou mais, na data da publicação desta Lei, ou que, já congelados na data da publicação desta Lei, depois de completarem 3 (três) anos, contados a partir da data de congelamento.

$\S 1^{\circ}$ Em qualquer caso, é necessário o consentimento dos genitores.

$\S 2^{\circ}$ Instituições de pesquisa e serviços de saúde que realizem pesquisa ou terapia com células-tronco embrionárias humanas deverão submeter seus projetos à apreciação e aprovação dos respectivos comitês de ética em pesquisa.

$\S 3^{\circ}$ É vedada a comercialização do material biológico a que se refere este artigo e sua prática implica o crime tipificado no art. 15 da Lei n. ${ }^{\circ}$ 9.434, de 4 de fevereiro de 1997.

3 ADI 3.510/DF. Rel. Min. Carlos Ayres Brito. Julg. 29/05/2008. Despacho do Rel. Min. Carlos Ayres Brito, em 19/12/2006. Para uma descrição detalhada do caso vide: BARROSO, Luís Roberto. O Novo Direito Constitucional Brasileiro: contribuições para a construção teórica e prática da jurisdição constitucional no Brasil. Belo Horizonte: Fórum, 2012. p. 395-420. Vide também: VALLE, Vanice Regina Lírio do (Org.). Audiências Públicas e Ativismo: diálogo social no STF. Belo Horizonte: Fórum, 2012. p. 63-70. 
(manhã e tarde), com a participação das partes, dos amici curiae e dos experts arrolados na petição inicial, somando um total (a favor e contra) de vinte e dois participantes.

Os debates, no entanto, não foram permitidos pelo ministro relator que, por diversas vezes, ressaltou que as exposições deveriam ser eminentemente técnicas, devendo os participantes absterem-se de considerações morais ou políticas ${ }^{4}$. Segundo o ministro relator, o espaço adequado para o debate seria o momento do julgamento em plenário. Dessa forma, a audiência pública foi uma sessão mais expositiva, fundada nas explanações científicas dos especialistas, do que uma sessão eminentemente deliberativa, com questionamentos e troca de argumentos. Após as exposições dos experts, foi aberta a possibilidade de intervenção de outros ministros para que eles pudessem fazer perguntas aos especialistas, dando sempre direito à parte contrária de também expor, por igual tempo, as suas considerações.

Em relação ao mérito da ação, como ficou demonstrado no curso do processo, não existe consenso científico (biológico), tampouco filosófico (moral), sobre quando se inicia a vida. Algumas posições defendem que a vida se inicia com a fecundação (como defendeu, por exemplo, a Procuradoria-Geral da República); outros defendem que a vida começa com a nidação (a fixação do embrião no útero); a Suprema Corte dos Estados Unidos e o Conselho de Ética Francês entendem que a vida se inicia quando o feto já tem condições de existir sem a mãe (entre a $24^{\mathrm{a}}$ e a $26^{\mathrm{a}}$ semana de gestação) (BARROSO, 2012, p. 403). Ou seja, há uma pluralidade de concepções sobre quando se dá o início da vida e diferentes fundamentações morais para tais concepções. Todas elas têm em comum fundadas razões biológicas e morais para se sustentarem. Vale dizer, todas essas diferentes concepções sobre quando se inicia a vida são, apesar de divergentes, razoavelmente defensáveis na esfera pública (RAWLS, 1993, p. 225-227). Há, portanto, nesse caso, o que Jeremy Waldron chamou de “desacordo moral razoável” (WALDRON, 1999, p. 149-153).

Diante de desacordos morais razoáveis, o papel do Estado não deve ser o de escolher um padrão moral e impô-lo a todos. Ao contrário, o papel do Estado deve ser o de assegurar que cada indivíduo leve sua vida da forma que escolher, respeitando as crenças e os valores individuais de seus cidadãos, garantindo-lhes, assim, sua liberdade e autonomia privada. E foi exatamente isso que a Lei n. ${ }^{\circ} 11.105 / 2005 \mathrm{fez}$, pois ela exige, em seu art. $5^{\circ}, \S 1^{\circ}$, em qualquer caso, o consentimento dos genitores. Ou seja, somente pode haver pesquisas com células-tronco embrionárias a partir dos embriões inviáveis ou congelados há mais de três anos, devendo haver, em qualquer dos casos, o prévio consentimento dos genitores. Da mesma forma, os pesquisadores e médicos também têm

\footnotetext{
${ }^{4}$ ADI 3.510/DF. Rel. Min. Carlos Ayres Brito. Julg. 29/05/2008. Notas taquigráficas p. 55/63/71.
} 
autonomia para realizar ou não esse tipo de pesquisa, e caso decidam pela utilização das célulastronco, deverão submeter seus projetos aos respectivos comitês de ética.

Durante o julgamento em plenário, houve a apresentação do relatório, foram realizadas as sustentações orais e, em seguida, votaram os ministros. A decisão do Supremo Tribunal Federal nesse caso, como tem sido habitual, foi fundamentada em diferentes razões. $\mathrm{O}$ ministro relator Carlos Ayres Britto justificou seu voto basicamente com os argumentos de que a proteção da vida é conferida à pessoa nativiva; as células-tronco embrionárias oferecem maior contribuição por serem células pluripotentes; é dever do Estado garantir o direito à saúde e a livre atividade científica. Acompanharam o ministro relator os ministros Carmen Lúcia, Joaquim Barbosa, Ellen Gracie, Marco Aurélio e Celso de Mello. O ministro Eros Grau votou pela improcedência da ação, condicionando seu voto a ressalvas por ele apresentadas.

De forma diferente decidiram os ministros Menezes Direito e Ricardo Lewandowski, julgando parcialmente procedente o pedido da Ação Direta de Inconstitucionalidade 3.510, a fim de que somente fossem autorizadas pesquisas com embriões humanos quando não haja sua destruição nem tenham seu potencial de desenvolvimento comprometido.

Por fim, os ministros Cezar Peluso e Gilmar Mendes votaram pela improcedência do pedido da ação, desde que houvesse prévia submissão das pesquisas com células-tronco embrionárias a um órgão central de controle subordinado ao Ministério da Saúde.

Diante disso, o julgamento resultou, por maioria de votos, na improcedência do pedido da Ação Direta de Inconstitucionalidade 3.510 e na consequente manutenção da Lei de Biossegurança, tal qual ela havia sido redigida e aprovada pelo Congresso Nacional.

Desde então, o julgamento da Ação Direta de Inconstitucionalidade 3.510 tem sido celebrado como um marco na abertura do Supremo Tribunal Federal à sociedade e tomado como exemplo na realização de audiências públicas e admissão de amici curiae como instrumentos de diálogo.

\section{AS AUDIÊNCIAS PÚBLICAS E OS AMICI CURIAE (QUANDO TAMBÉM ACEITOS CONJUNTAMENTE COM AS AUDIÊNCIAS PÚBLICAS) INFLUENCIAM AS DECISÕES DOS MINISTROS DO SUPREMO TRIBUNAL FEDERAL?}

Desde a realização da primeira audiência pública no caso da Lei de Biossegurança, em 2007, o Supremo Tribunal Federal já realizou várias outras audiências públicas e aceitou inúmeros amici curiae em diferentes outros casos. Para tanto, o Supremo Tribunal Federal regulamentou a 
realização das audiências públicas em seu regimento interno ${ }^{5}$, demonstrando a permanência de sua abertura a um diálogo direto com o povo e as instituições. É fundamental, no entanto, verificar de que maneira o Supremo Tribunal Federal tem encarado as audiências públicas e os amici curiae (quando também aceitos conjuntamente com as audiências públicas) como instrumentos de abertura ao diálogo e à participação popular. Ou seja, é preciso conferir se essa abertura do Supremo Tribunal Federal à participação popular por meio de audiências públicas e de amici curiae de fato leva em conta as informações e os argumentos apresentados por cidadãos e instituições chamados e aceitos a participarem da ação sob julgamento. Daí a pergunta que inaugura o presente ponto: as audiências públicas e os amici curiae (quando também aceitos conjuntamente com as audiências públicas) influenciam as decisões dos ministros do Supremo Tribunal Federal? Este trabalho apresenta uma resposta, ainda que parcial, a essa pergunta. Para se chegar a essa resposta o seguinte caminho foi percorrido:

- Análise de casos: exame dos casos definitivamente julgados pelo Supremo Tribunal Federal, com acórdãos já publicados até o momento da escrita deste trabalho, em que houve audiência pública. Tais casos são: Lei de Biossegurança (ADI 3.510), Importação de Pneus Usados (ADPF 101), Interrupção da Gestação de Feto Anencefálico (ADPF 54), Saúde/Concessão de Medicamentos (STA 36, STA 175, STA 211, STA 278, SS 2.361, SS 2.944, SS 3.345, SS 3.355, SL 47 e SL 64) e Cotas (ADPF 186 e REx 597.285) ${ }^{6}$. A análise desses casos se deteve sobre as audiências públicas e as razões nelas apresentadas por seus participantes. Em alguns casos o

\footnotetext{
${ }^{5}$ A regulamentação da realização das audiências públicas pelo Supremo Tribunal Federal foi promovida pela Emenda Regimental $n^{\circ}$ 29/2009.

${ }^{6}$ Conforme explicitado, a análise de casos desta pesquisa abrange os casos definitivamente julgados pelo Supremo Tribunal Federal e que tenham seus acórdãos já publicados. Para os fins deste trabalho, esse universo da pesquisa abarcou os casos da Lei de Biossegurança (ADI 3.510), Importação de Pneus Usados (ADPF 101), Interrupção da Gestação de Feto Anencefálico (ADPF 54), Saúde/Concessão de Medicamentos (STA 36, STA 175, STA 211, STA 278, SS 2.361, SS 2.944, SS 3.345, SS 3.355, SL 47 e SL 64) e Cotas (ADPF 189 e REx 597.285). Tal análise, no entanto, pode e deve ser expandida à medida que se concluam os julgamentos e se publiquem os acórdãos dos casos ainda pendentes de julgamento e que utilizaram em seu curso audiências públicas e amici curiae (quando também aceitos conjuntamente com as audiências públicas). Tal expansão permitiria a continuidade das análises e avaliações sobre a forma como o Supremo Tribunal Federal tem encarado os instrumentos objeto de análise como mecanismos de abertura para a participação popular, bem como se essas formas de participação realmente têm influenciado as decisões dos ministros. Mais do que isso, o prosseguimento dessa pesquisa empírica permitiria ainda comparar e avaliar se a maneira de o Supremo Tribunal Federal utilizar as audiências públicas e os amici curiae tem se aprimorado, mantido-se igual ou, eventualmente, piorado. Além disso, outros subcritérios de avaliação poderiam ser incorporados, como, por exemplo, a verificação de como os ministros do Supremo Tribunal Federal eventualmente utilizaram os argumentos suscitados nas audiências públicas e pelos amici curiae para fundamentar seu votos. Nesse sentido, verificar se haveria (i) uma absorção mecânica dos argumentos ou (ii) um desatamento e "diálogo" com os argumentos e as razões apresentados seria exemplo de novos subcritérios que incrementariam a presente pesquisa. De todo modo, para os fins deste estudo, o universo da pesquisa foi delimitado pelos casos julgados com acórdãos já publicados até o momento de escrita do presente estudo, conforme explicado acima.
} 
Supremo Tribunal Federal, além das audiências públicas, também admitiu amici curiae. Nesses casos, quando as razões dos amici curiae foram apresentadas e disponibilizadas por escrito, elas também foram analisadas. Os dados foram coletados do site do Supremo Tribunal Federal e das páginas de internet que hospedam os vídeos com as gravações das audiências públicas - TV Justiça/página oficial do STF no YouTube.

- Metodologia de análise: definidos os casos a serem examinados, estabeleceu-se como método de análise a comparação entre (i) as razões e argumentos expostos nas audiências públicas e pelos amici curiae (quando também aceitos conjuntamente com as audiências públicas) e (ii) as razões e argumentos dos votos dos ministros do Supremo Tribunal Federal. Essa comparação permite identificar se as razões e os argumentos expostos nas audiências públicas e pelos amici curiae (quando também aceitos conjuntamente com as audiências públicas) foram levados em consideração pelos ministros em suas decisões. A avaliação dessa comparação é feita segundo dois critérios, um objetivo e outro subjetivo. O critério objetivo consiste na verificação de referências expressas às audiências públicas e aos amici curiae na fundamentação dos votos dos ministros. O critério subjetivo consiste em analisar se na fundamentação dos votos dos ministros do Supremo Tribunal Federal há a invocação de razões e argumentos iguais ou semelhantes àqueles apresentados nas audiências públicas e pelos amici curiae, para o embasamento de suas decisões, ainda que inexista referência expressa a eles.

- Conclusão a partir dos resultados obtidos: após a comparação e a avaliação da comparação, é feita uma conclusão a partir dos resultados obtidos.

Diante disso, os casos objeto da pesquisa foram assim entabulados: 
AS AUDIÊNCIAS PÚBLICAS E OS AMICI CURIAE INFLUENCIAM AS DECISÕES DOS MINISTROS DO SUPREMO TRIBUNAL FEDERAL? E POR QUE ISSO DEVE(RIA) IMPORTAR?

\subsection{TABELA GERAL}

\begin{tabular}{|c|c|c|c|c|c|}
\hline & Auditência Pública & Amicus Curie & $\begin{array}{c}\text { Razöes do Amicus } \\
\text { Curige }\end{array}$ & Data de Julgamento & Publicaçă̄o Acórdăo \\
\hline Lei de Blossegurança: ADI 3.510 & $20 / 04 / 07$ & Sim & Sim & $29 / 05 / 08$ & $28 / 05 / 10$ \\
\hline $\begin{array}{l}\text { Importação de pneus usados: } \\
\text { ADPF } 101\end{array}$ & $27 / 06 / 08$ & Sim & Sim & $24 / 06 / 09$ & $04 / 06 / 12$ \\
\hline $\begin{array}{l}\text { Interrupçăo da Gestaçăo de } \\
\text { Feto Anencefálico: ADPF } 54\end{array}$ & 26 e $28 / 08 / 2008$ & Negados & - & $12 / 04 / 12$ & $30 / 04 / 13$ \\
\hline $\begin{array}{l}\text { Saúde/Concessllo de } \\
\text { Medicamentos: STA 36, STA } \\
\text { 175, STA 211, STA 278, SS } \\
\text { 2.361, SS 2.944, SS 3.345, SS } \\
\text { 3.355, SL } 47 \text { e SL 64 }\end{array}$ & $\begin{array}{c}27,28 \mathrm{e} \\
29 / 04 / 2009 ; 04,06 \mathrm{e} \\
07 / 05 / 2009\end{array}$ & $\begin{array}{l}\text { Não houve } \\
\text { participação }\end{array}$ & - & $17 / 03 / 10$ & $30 / 04 / 10$ \\
\hline $\begin{array}{c}\text { Cotas: ADPF 186 e REXT } \\
597.285\end{array}$ & 03,04 e $05 / 03 / 2012$ & Sim* & Sim & $\begin{array}{l}26 / 04 / 2012 \mathrm{e} \\
09 / 05 / 2012^{* *}\end{array}$ & $\begin{array}{l}20 / 10 / 2014 \text { e } \\
18 / 03 / 2014\end{array}$ \\
\hline Lei Seca: ADI 4103 & 07 e $14 / 05 / 2012$ & Sim & Sim & Não ocorreu o julgamento & _ \\
\hline Amianto: ADI 3937 e 3357 & 24 e $31 / 08 / 2012$ & Sim & Sim & Julgamento suspenso & - \\
\hline $\begin{array}{c}\text { TV por Assinatura: ADI 4679, } \\
4747 \text { e } 4756\end{array}$ & 18 e $25 / 02 / 2013$ & $\operatorname{Sim} * * *$ & Sim & Julgamento suspenso & - \\
\hline $\begin{array}{c}\text { Campo Eletromagnético: REXT } \\
627189 \\
\end{array}$ & 06,07 e $08 / 03 / 2013$ & Sim & Não & Não ocorreu o julgamento & - \\
\hline $\begin{array}{l}\text { Queimada em Canavial: REXT } \\
586224 \\
\end{array}$ & $22 / 04 / 13$ & Negado & - & $09 / 03 / 15$ & $\begin{array}{l}\text { Acórdão não } \\
\text { publicado }\end{array}$ \\
\hline $\begin{array}{c}\text { Financiamento de Campanhas } \\
\text { Eleitorais: } A D I 4640\end{array}$ & 17 e $24 / 06 / 2013$ & $\mathrm{Sim}$ & $\mathrm{Sim}$ & Julgamento suspenso & - \\
\hline Regime Prisional: REXT 641320 & 27 e $28 / 05 / 2013$ & Sim & Sim & Não ocorreu o julgamento & - \\
\hline $\begin{array}{c}\text { Biografias Nắo Autorizadas: ADI } \\
4815\end{array}$ & 21 e $22 / 11 / 2013$ & $\mathrm{Sim}$ & $\mathrm{Sim}$ & Não ocorreu o julgamento & - \\
\hline Mais Médicos: ADI 5035 e 5037 & 25 e $26 / 11 / 2013$ & $\begin{array}{l}\text { Não houve } \\
\text { participação }\end{array}$ & - & Não ocorreu o julgamento & - \\
\hline $\begin{array}{c}\text { Direitos Autorais: ADI } 5062 \mathrm{e} \\
5065\end{array}$ & $17 / 03 / 14$ & $\begin{array}{l}\text { Não houve } \\
\text { participação }\end{array}$ & - & Não ocorreu o julgamento & - \\
\hline $\begin{array}{l}\text { Ensino Religioso em Escolas } \\
\text { Públicas: ADI } 4439\end{array}$ & $\begin{array}{l}\text { Realização prevista } \\
\text { para o dia 15/06/2015 }\end{array}$ & Sim & Nã。 & Não ocorreu o julgamento & - \\
\hline
\end{tabular}

*Destaque-se que das duas ações - ADPF 186 e REXT 597.285 - houve participação de amicus curiae apenas na ADPF 186.

**A ADPF 186 foi julgada em 26/04/2012 e o REXT 597.285 foi julgado em 09/05/2012. ***Ressalte-se que das três ações - ADI 4679, ADI 4747 e ADI 4756 - a ADI 4679 foi a única que não contou com a participação de amicus curiae.

A coleta e apresentação dos dados para a realização da comparação entre (i) as razões e argumentos expostos nas audiências públicas e pelos amici curiae (quando também aceitos conjuntamente com as audiências públicas) e (ii) as razões e argumentos dos votos dos ministros do Supremo Tribunal Federal foram assim entabuladas: 
2.2 LEI DE BIOSSEGURANÇA (ADI 3.510)

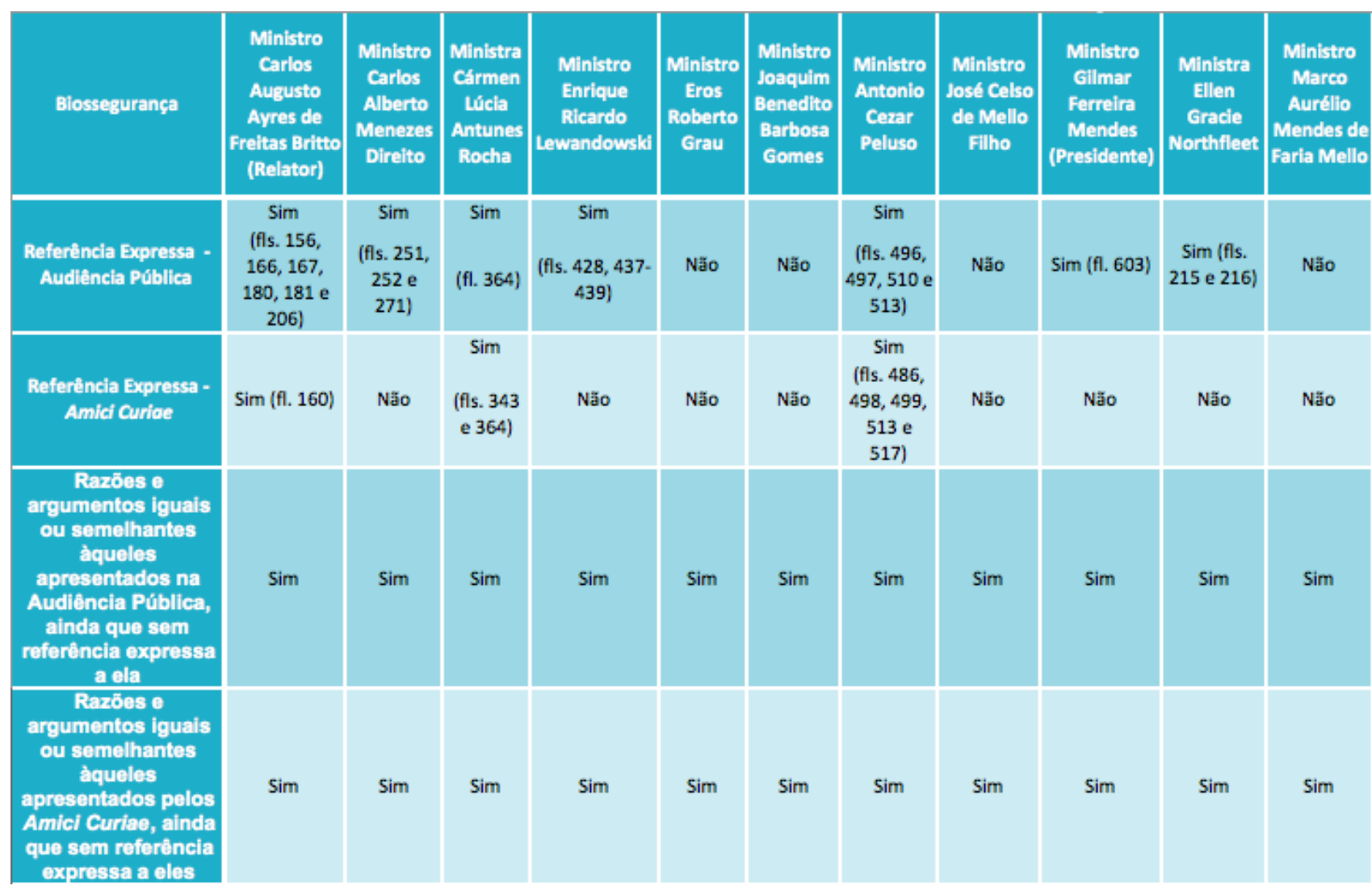

A análise da comparação feita no caso da Lei de Biossegurança (ADI 3.510) mostra que sete dos 11 ministros do Supremo Tribunal Federal fizeram referências expressas às razões e aos argumentos apresentados em audiência pública. Por outro lado, apenas três dos 11 ministros fizeram referências expressas às razões e aos argumentos apresentados pelos amici curiae.

No entanto, todos os ministros valeram-se de razões e argumentos apresentados em audiência pública e pelos amici curiae para fundamentar suas decisões, ainda que não tenham feito referência expressa a eles, conforme se verifica nos dois últimos campos da tabela, intitulados "Razões e argumentos iguais ou semelhantes àqueles apresentados na Audiência Pública, ainda que sem referência expressa a ela" e "Razões e argumentos iguais ou semelhantes àqueles apresentados pelos Amici Curiae, ainda que sem referência expressa a eles”. 


\subsection{IMPORTAÇÃO DE PNEUS USADOS (ADPF 101)}

\begin{tabular}{|c|c|c|c|c|c|c|c|c|c|c|c|}
\hline Pneus & \begin{tabular}{|c|} 
Ministra \\
Cármen \\
Lúcla \\
Antunes \\
Rocha \\
(Relatora)
\end{tabular} & $\begin{array}{l}\text { Ministro } \\
\text { Carlos } \\
\text { Alberto } \\
\text { Menezes } \\
\text { Direito }\end{array}$ & \begin{tabular}{|c|} 
Ministro \\
Enrique \\
Ricardo \\
Lewandowski
\end{tabular} & $\begin{array}{l}\text { Ministro } \\
\text { Joaquim } \\
\text { Benedito } \\
\text { Barbosa } \\
\text { Gomes }\end{array}$ & $\begin{array}{c}\text { Ministro } \\
\text { Carlos } \\
\text { Augusto } \\
\text { Ayres de } \\
\text { Freitas Britto }\end{array}$ & \begin{tabular}{c|} 
Ministra \\
Ellen \\
Gracie \\
Northfleet
\end{tabular} & $\begin{array}{c}\text { Ministro } \\
\text { Marco } \\
\text { Aurélio } \\
\text { Mendes de } \\
\text { Faria Mello }\end{array}$ & $\begin{array}{c}\text { Ministro } \\
\text { Eros Roberto } \\
\text { Grau }\end{array}$ & $\begin{array}{c}\text { Ministro } \\
\text { José Antonio } \\
\text { Dias Toffoli }\end{array}$ & $\begin{array}{l}\text { Ministro } \\
\text { Gilmar } \\
\text { Ferreira } \\
\text { Mendes } \\
\text { (Presidente) }\end{array}$ & $\begin{array}{c}\text { Ministro } \\
\text { Antonio } \\
\text { Cerar Peluso }\end{array}$ \\
\hline $\begin{array}{l}\text { Referência Expressa - } \\
\text { Audiência Pública }\end{array}$ & $\begin{array}{c}\text { Sim (fls. 40, } \\
73,122 \\
172-191 \text { ) }\end{array}$ & Não & $\begin{array}{l}\text { Acompanhou } \\
\text { a Relatora }\end{array}$ & Nåo & Não & Näo & Nåo & Não & $\begin{array}{l}\text { Atuou no } \\
\text { feito }\end{array}$ & Sim (fl. 257) & Ausente \\
\hline $\begin{array}{c}\text { Referência Expressa - } \\
\text { Amici Curioe } \\
\end{array}$ & Não & Não & $\begin{array}{c}\text { Acompanhou } \\
\text { a Relatora }\end{array}$ & $\begin{array}{l}\text { Sim (fls. } \\
\text { 221) }\end{array}$ & Não & Não & Não & Não & $\begin{array}{l}\text { Atuou no } \\
\text { feito }\end{array}$ & Sim (fl. 243) & Ausente \\
\hline $\begin{array}{c}\text { Razóes e } \\
\text { argumentos iguais } \\
\text { ou semelhantes } \\
\text { àqueles } \\
\text { apresentados na } \\
\text { Audiência Pública, } \\
\text { ainda que sem } \\
\text { referência expressa } \\
\text { a ela } \\
\end{array}$ & Sim & Não & $\begin{array}{l}\text { Acompanhou } \\
\text { a Relatora }\end{array}$ & Sim & Sim & Sim & Sim & Não & $\begin{array}{l}\text { Atuou no } \\
\text { feito }\end{array}$ & Sim & Ausente \\
\hline $\begin{array}{c}\text { Razōes e } \\
\text { argumentos iguais } \\
\text { ou semelhantes } \\
\text { àqueles } \\
\text { apresentados pelos } \\
\text { Amici Curiae, ainda } \\
\text { que sem referência } \\
\text { expressa a eles }\end{array}$ & Sim & Não & $\begin{array}{l}\text { Acompanhou } \\
\text { a Relatora }\end{array}$ & Sim & Sim & Sim & Sim & Não & $\begin{array}{l}\text { Atuou no } \\
\text { feito }\end{array}$ & Sim & Ausente \\
\hline
\end{tabular}

A análise da comparação feita no caso da Importação de Pneus Usados (ADPF 101) mostra que dos 11 ministros do Supremo Tribunal Federal, nove participaram do julgamento. Desses nove ministros, dois fizeram referências expressas às razões e aos argumentos apresentados em audiência pública, um ministro acompanhou a ministra relatora e os outros seis ministros não fizeram qualquer menção expressa às razões e argumentos apresentados em audiência pública. Por outro lado, apenas dois dos nove ministros que participaram do julgamento referenciaram expressamente em seu voto razões e argumentos apresentados pelos amici curiae ${ }^{7}$.

No entanto, seis dos nove ministros que integraram o julgamento valeram-se de razões e argumentos apresentados em audiência pública e pelos amici curiae para fundamentar suas decisões, ainda que sem referência expressa a eles, conforme se verifica nos dois últimos campos da

\footnotetext{
${ }^{7}$ Destaque-se que no julgamento da ADPF 101 foram aceitos 14 amici curiae: Pneus Hauer do Brasil Ltda; Associação Brasileira da Indústria de Pneus Remoldados - Abip; Associação Nacional da Indústria de Pneumático - Anip; Pneuback Indústria e Comércio de Pneus Ltda; Instituto Brasileiro do Meio Ambiente e dos Recursos Naturais Renováveis - Ibama; Tal Remoldagem de Pneus Ltda; BS Colway Pneus Ltda; Conectas Direitos Humanos; Justiça Global; Associação de Proteção do Meio Ambiente de Cianorte - Apromac; Associação Brasileira do Segmento de Reforma de Pneus - ABR; Associação de Defesa da Concorrência Legal e dos Consumidores Brasileira - ADCL; Líder Remoldagem e Comércio de Pneus Ltda e RIBOR - Importação, Exportação, Comércio e Representações Ltda. No entanto, foram disponibilizadas as petições, com as razões escritas, de apenas cinco deles: Associação Brasileira da Indústria de Pneus Remoldados - Abip; Associação Nacional da Indústria de Pneumático - Anip; Instituto Brasileiro do Meio Ambiente e dos Recursos Naturais Renováveis - Ibama; Conectas Direitos Humanos; Associação de Proteção do Meio Ambiente de Cianorte - Apromac. Dessa forma, a presente pesquisa foi obrigada a, neste caso, restringir as análises dos amici curiae àqueles que tiveram suas petições e razões escritas disponibilizadas.
} 
tabela. Apenas um ministro (ministro Menezes Direito) não fez qualquer tipo de referência, expressa ou tácita, e outro ministro acompanhou o voto da ministra relatora.

\subsection{INTERRUPÇÃO DA GESTAÇÃO DE FETO ANENCEFÁLICO (ADPF 54)}

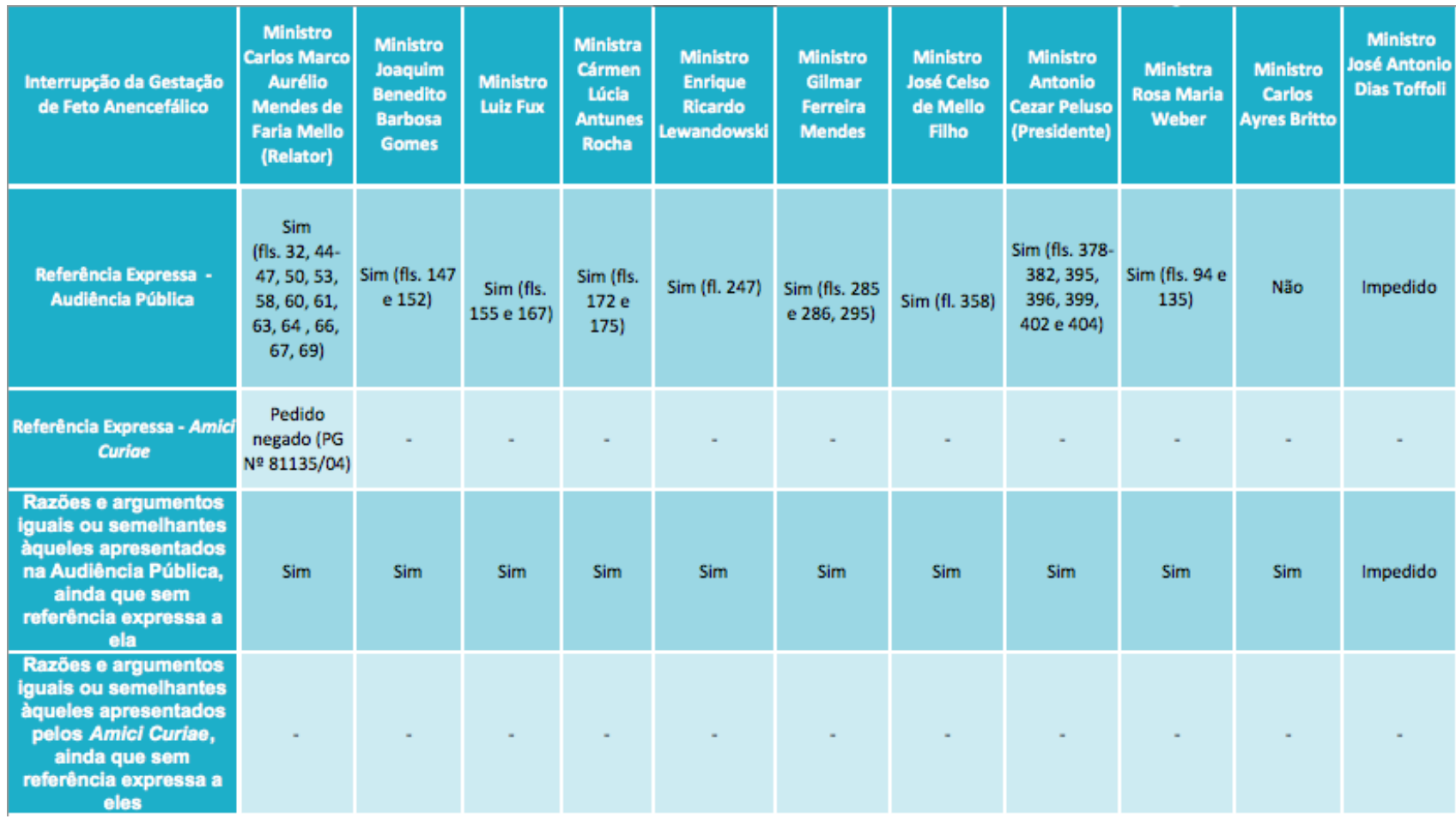

A análise da comparação feita no caso da Interrupção da Gestação de Feto Anencefálico (ADPF 54) mostra que, dos 11 ministros do Supremo Tribunal Federal, 10 participaram do julgamento. Desses 10 ministros, nove fizeram referências expressas às razões e aos argumentos apresentados em audiência pública - apenas um deles não o fez. Destaque-se que, nesse caso, não foi admitida a participação de amicus curiae.

O único ministro que não fez referência expressa às razões e argumentos apresentados em audiência pública, no entanto, valeu-se delas, ainda que de forma tácita, conforme se verifica no penúltimo campo da tabela, intitulado "Razões e argumentos iguais ou semelhantes àqueles apresentados na Audiência Pública, ainda que sem referência expressa a ela”. 
2.5 SAÚDE/CONCESSÃO DE MEDICAMENTOS (STA 36, STA 175, STA 211, STA 278, SS 2.361, SS 2.944, SS 3.345, SS 3.355, SL 47 E SL 64)

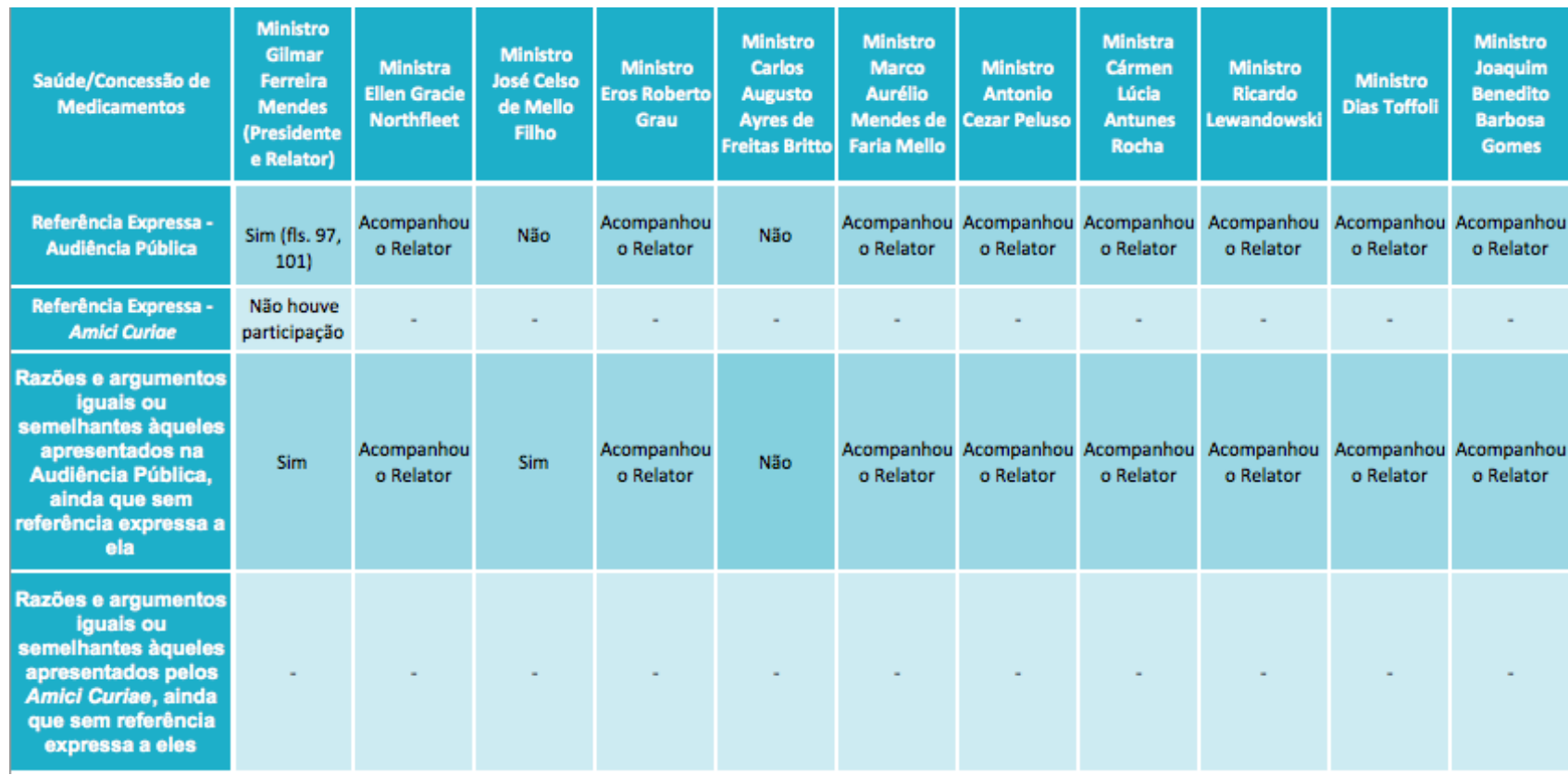

No caso da Saúde/Concessão de Medicamentos (STA 36, STA 175, STA 211, STA 278, SS 2.361, SS 2.944, SS 3.345, SS 3.355, SL 47 e SL 64), dos 11 ministros do Supremo Tribunal Federal, oito acompanharam o voto do ministro relator, o qual fez referências expressas às razões e aos argumentos apresentados na audiência pública. Destaque-se que o ministro Celso de Mello apresentou voto em apartado e, apesar de não ter feito referência expressa à audiência pública, valeu-se de razões e argumentos nela apresentados para fundamentar sua decisão, conforme se verifica no penúltimo campo da tabela, intitulado "Razões e argumentos iguais ou semelhantes àqueles apresentados na Audiência Pública, ainda que sem referência expressa a ela”. Um único ministro (ministro Ayres Britto) não valeu-se das razões, expressas ou não, expostas em audiência pública. Destaque-se que nesse caso não houve a participação de amicus curiae. 


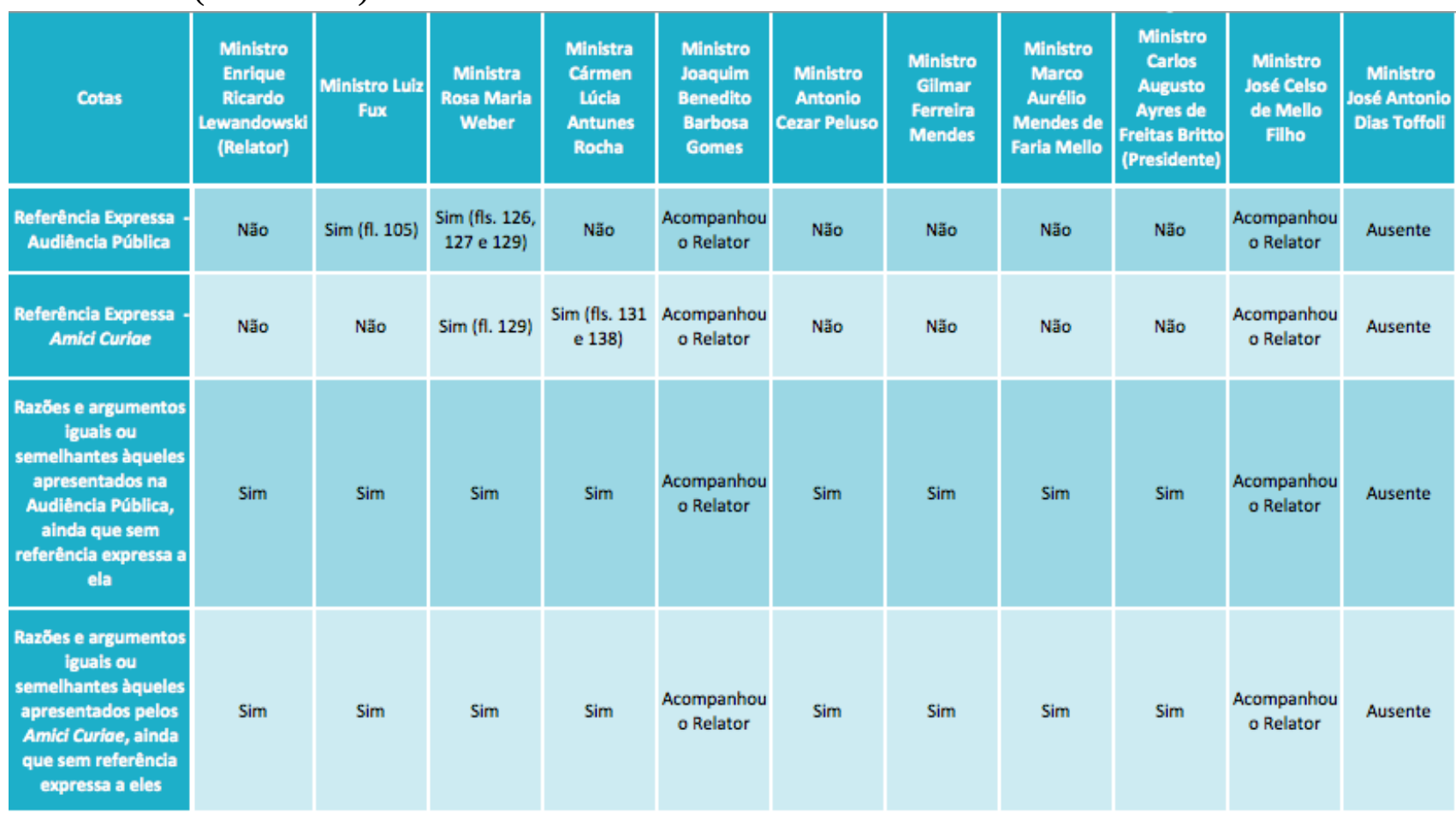

A análise da comparação feita no caso das Cotas (ADPF 186) mostra que, dos 11 ministros do Supremo Tribunal Federal, dez participaram do julgamento. O ministro relator não fez referência expressa às razões e aos argumentos apresentados em audiência pública e nem pelos amici curiae. Dois ministros acompanharam o ministro relator. Cinco ministros não fizeram qualquer referência expressa às razões e aos argumentos apresentados em audiência pública e nem pelos amici curiae. Apenas dois ministros fizeram referência expressa às razões e aos argumentos apresentados em audiência pública, mas apenas um deles fez referência expressa às razões e aos argumentos apresentados pelos amici curiae. Ou seja, apenas um ministro fez referência expressa às razões e aos argumentos apresentados pelos amici curiae.

No entanto, dos dez ministros que julgaram o feito, oito valeram-se de razões e argumentos iguais ou semelhantes àqueles apresentados na audiência pública e pelos amici curiae, ainda que sem referência expressa a eles, sendo que os outros dois ministros restantes acompanharam o ministro relator.

\subsection{CONCLUSÃO A PARTIR DOS RESULTADOS OBTIDOS}

Os dados coletados e analisados demonstram que as audiências públicas e os amici curiae (quando também aceitos conjuntamente com as audiências públicas) influenciam sim as decisões dos ministros do Supremo Tribunal Federal. É de destacar-se, no entanto, que em suas decisões os 
ministros fazem mais referências expressas às razões e aos argumentos apresentados nas audiências públicas do que às razões e aos argumentos apresentados pelos amici curiae. De toda forma, praticamente todos os ministros em todos os casos analisados valeram-se, de forma expressa ou não, das razões e dos argumentos expostos em audiência pública ou pelos amici curiae. Esses dados demonstram a efetiva permeabilidade do Supremo Tribunal Federal à participação de pessoas e instituições que se somam à análise dos casos sob julgamento. Essa abertura do Supremo Tribunal Federal à sociedade por meio de audiências públicas e amici curiae deve, assim, ser reconhecida como algo fundamental, pois efetivamente colabora com a tomada de decisão pelos ministros quando do julgamento dos casos.

\section{A REALIZAÇÃO DE AUDIÊNCIAS PÚBLICAS E AS INTERVENÇÕES DE AMICI CURIAE TÊM POSSIBILITADO UM DIÁLOGO EFETIVO ENTRE O SUPREMO TRIBUNAL FEDERAL E A SOCIEDADE?}

A forma como tem se realizado as audiências públicas e a admissão de amici curiae mostra que, se quisermos ter um espaço deliberativo, efetivamente dialógico, no qual haja uma profunda discussão e troca de argumentos, há muito a se melhorar. Vale dizer, do ponto de vista de uma abertura democrático-deliberativa e dialógica, a decisão do Supremo Tribunal Federal de utilizar instrumentos de participação de outros atores em julgamentos de questões constitucionais relevantes é muito bem-vinda. Por outro lado, a forma como tem se dado a utilização desses instrumentos, bem como a performance deliberativa do Supremo Tribunal Federal, precisa ser aprimorada.

A escolha dos participantes da audiência pública e dos amici curiae é uma decisão discricionária do ministro relator $^{8}$. Vale dizer, cabe ao ministro relator convocar pessoas com notória experiência e autoridade no assunto, podendo, no entanto, haver requerimento por iniciativa própria de pessoas especialistas no assunto, para a ocorrência de audiência pública. No que se refere aos amigos da corte, eles solicitam seu ingresso no feito e o ministro relator é quem decide sobre a aceitação ou não do seu pedido de ingresso. Ou seja, o ministro relator tem um papel fundamental na promoção do debate público, pois ele possui a faculdade de possibilitar que diferentes vozes possam ser ouvidas e, principalmente, a de escolher e selecionar aquelas que se farão ouvir. Esse poder do ministro relator também pode, por outro lado, impossibilitar, restringir e até mesmo enviesar o debate.

\footnotetext{
${ }^{8}$ Audiência Pública: art. $9^{\circ}, \S 1^{\circ}$ e $\S 2^{\circ}$, art. $12-\mathrm{E}, \S 1^{\circ}$, art. $20, \S 1^{\circ}$ e $\S 2^{\circ}$, da Lei n. ${ }^{\circ} 9.868 / 1999$ e art. $6^{\circ}$, $\S 1^{\circ}$ da Lei 9.882/1999, art. 13, XVII, art. 21, XVII, entre outros, do Regimento Interno do Supremo Tribunal Federal. Amicus Curiae: art. $7^{\circ}, \S 2^{\circ}$ da Lei n. ${ }^{\circ} 9.868 / 1999$.
} 
No caso da Lei de Biossegurança (ADI 3.510), a decisão do ministro relator sobre a admissão ou recusa dos pedidos de ingresso na ação na condição de amicus curiae careceu de adequada fundamentação, pois não apontou as razões para a admissão ou rejeição dos postulantes. Tais motivos apareceram somente em momento posterior, no relatório do caso em que o ministro relator então declarou que aceitou a participação de determinados amici curiae com base em sua representação nacional. Foi, assim, uma escolha extremamente seletiva e pouco transparente. Se é certo que os amici curiae devem ser órgãos ou entidades de representação que exibam não apenas interesse, mas também conhecimento sobre o assunto (conforme exige a Lei n. ${ }^{\circ}$ 9.868/1999), por outro lado, a decisão do ministro relator de aceitá-los ou não como amigos da corte deve ser bastante clara em suas razões.

Diante dessa importante e decisiva competência do ministro relator, sua tarefa deve(ria) ser a de promover o maior e mais amplo debate sobre o tema, possibilitando que as diferentes vozes, opiniões e correntes de pensamento possam se manifestar sobre o assunto que esteja sob julgamento.

Além da escolha das pessoas e entidades que poderão participar do julgamento do caso, é preciso também destacar a necessidade de reformulação da metodologia de realização das audiências públicas. A forma como as audiências públicas têm sido realizadas não permite que elas sejam um efetivo espaço de deliberação, com a apresentação, troca e debate de informações e argumentos. Ao contrário, da forma como elas têm acontecido, as audiências se reduzem apenas e tão somente à exposição de diferentes posições em relação ao caso. Assim, as audiências públicas têm funcionado muito mais como um espaço de complementação informativa dos ministros do que como um ambiente destinado a um debate público robusto, em que as diferentes razões e argumentos podem ser destrinçados, desafiados, ratificados ou superados. Não é à toa que alguns ministros nem sequer fizeram qualquer tipo de referência às audiências públicas em seus votos.

Esse modo pouco deliberativo de conceber a audiência pública ficou claro, no caso da Lei de Biossegurança (ADI 3.510), nas diversas intervenções feitas pelo ministro relator Carlos Ayres Britto, ao vetar os possíveis debates e questionamentos que surgiram no decorrer da audiência pública. Mais do que isso, nesse caso o ministro relator exigiu que as exposições se restringissem a argumentos científicos, devendo ficar de fora argumentos jurídicos, políticos, éticos ou morais. Isso mostra o subaproveitamento da audiência pública como espaço de debate, de troca de argumentos não apenas científicos, mas também morais, já que a questão levantada pela ADI 3.510 era justamente uma questão moral - a de proteção da vida e da dignidade da pessoa humana. O argumento sustentado pelo ministro relator, de que o espaço adequado para o debate era o 
julgamento em plenário, tampouco se verificou verdadeiro. O debate não apenas não aconteceu entre os ministros - e raramente tal debate acontece - como, ainda que acontecesse, seria um debate apenas entre os julgadores e não entre eles e as partes, amigos da corte e especialistas.

Essa forma de encarar a audiência pública confunde as três diferentes fases deliberativas do processo de julgamento de um caso, quais sejam: fase pré-decisional, fase decisional e fase pósdecisional (MENDES, 2013, p. 105). São três momentos distintos do julgamento do caso, e que possibilitam avaliar o desempenho deliberativo da Corte de acordo com a peculiaridade de cada uma dessas fases, tendo como objetivo geral que a decisão seja produto de uma efetiva deliberação.

A fase pré-decisional é aquela na qual a tarefa deliberativa consiste na promoção de uma contestação pública sobre o caso. A fase decisional consiste no engajamento colegiado dos ministros para buscar as melhores razões e os argumentos públicos para fundamentar sua decisão. A fase pós-decisional consiste na decisão deliberativa escrita, que definirá a controvérsia e poderá (e deverá) ser novamente objeto de deliberação por parte de outros atores e instituições ${ }^{9}$. Nessas três fases há também uma distinção sobre quem delibera. Como as fases pré-decisional e pós-decisional possuem um caráter deliberativo externo, ou seja, a Corte discute com outros atores e instituições, os interlocutores são aqueles que formalmente ou informalmente endereçam argumentos públicos ao Tribunal, expressando suas posições públicas sobre o caso em julgamento (MENDES, 2013, p.106). A fase decisional tem um caráter deliberativo interno, ou seja, de troca de razões e argumentos entre os ministros, na qual não há participação dos interlocutores. Nessas diferentes fases, há distintas formas e locais de deliberação, cada uma delas enfrentando e exigindo padrões deliberativos específicos, conforme se verá a seguir.

A fase pré-decisional consiste no debate público sobre um caso submetido a julgamento. Esse debate deve contar com a participação de diversos atores políticos, individuais ou coletivos, que manifestarão suas posições públicas sobre o caso em apreço por meio dos mecanismos normativos e institucionais existentes. Diante disso, a audiência pública e os amici curiae são instrumentos relevantes, pois é por meio deles que esse debate público robusto também pode ser incentivado e promovido pela Corte. E, se cabe ao ministro relator a faculdade de realizar a audiência pública, convocar especialistas e aceitar os pedidos de ingresso como amigos da corte, seu papel deve ser o de promover o maior e mais amplo debate para coletar o máximo possível de

\footnotetext{
${ }^{9}$ Isso não significa, no entanto, que a fase pós-decisional de um caso é a pré-decisional de outro. Apesar de ambas serem fases de uma deliberação de caráter externo (entre o Tribunal e diferentes interlocutores), a fase pré-decisional está vinculada a um caso específico e a fase pós-decisional já incorporou ou superou uma série de razões e argumentos. Cada fase, portanto, possui facetas e características próprias, ainda que após a decisão o debate possa permanecer vivo.
} 
argumentos e possibilitar que tais argumentos sejam publicamente desafiados e refinados (MENDES, 2013, p. 108). Quando o ministro relator realiza a audiência pública e aceita o ingresso de amici curiae, mas impede o debate, ele reduz o potencial deliberativo desses instrumentos e espaços e ainda restringe a importância da fase pré-decisional.

A fase decisional consiste no engajamento colegiado dos ministros, para levar em conta todas as posições apresentadas à Corte, buscar a construção da melhor resposta baseada em princípios e na busca pelo consenso ou, quando esse consenso não for possível, na minimização do dissenso (MENDES, 2013, p. 109). Nesse sentido, a deliberação interna entre os ministros não deve ser um duelo verbal ou uma competição de erudição, mas uma empreitada sincera pela construção da melhor decisão, baseada em razões públicas, fundadas em princípios profundamente esquadrinhados e justificados. Essa fase decisional de engajamento colegiado é hoje praticamente inexistente no Supremo Tribunal Federal. Não há um debate intra muros entre os ministros e, quando há debate entre eles em plenário, em geral boa parte deles já firmou sua posição sobre o caso ou até mesmo escreveu seu voto. Nesse sentido, falta um momento para que os ministros possam se reunir e discutir coletivamente sobre os argumentos apresentados na fase pré-decisional.

A fase pós-decisional traduz os compromissos éticos da deliberação em uma peça escrita (MENDES, 2013, p. 109). Para além de uma decisão fundamentada, ela deve ainda ser sensível e legível para o público, não sendo suficiente a mera abordagem dos argumentos dos litigantes. Uma corte é consciente da sua falibilidade e da inevitável continuação da deliberação na esfera pública e em possíveis casos futuros. A decisão deve transmitir essa compreensão, evitando qualquer divisão entre iluminados e ignorantes, demonstrando sempre um respeito profundo por aqueles que serão afetados por ela independentemente do polo que ocuparam (MENDES, 2013, p. 110). Essa decisão escrita deve ter a qualidade esperada da função de destaque que uma corte constitucional exerce, e é desejável que seja uma decisão supraindividual, produto da transformação do engajamento e debate colegiado em uma decisão deliberativa tomada por vários julgadores diante de diversos argumentos que foram apresentados. Nesse sentido, do ponto de vista formal, a decisão deliberativa escrita pode ser prolatada tanto como uma única voz do tribunal (per curiam) quanto como uma decisão fracionária individual (pure seriatim), ou, ainda, como uma decisão intermediária, composta pela opinião da maioria mas com opiniões divergentes (MENDES, 2013, p. 111). Essa exigência de uma decisão deliberativa escrita, seja ela única como uma opinião da corte (per curiam), fracionada pela decisão individual dos ministros (pure seriatim) ou mista, mostra como o compromisso com a deliberação não pode ser inferido apenas do ponto de vista formal (MENDES, 2013, p. 111-112). 
O modelo decisório do Supremo Tribunal Federal não é hoje o de uma decisão da corte (per curiam), mas sim o de decisões fracionárias individuais (pure seriatim). Vale dizer, ainda que haja um debate público prévio à tomada de decisão, os ministros decidem os casos de forma individual, sem um engajamento colegiado e em geral fechados em seus gabinetes. Cada ministro toma sua decisão individual e somam-se os dispositivos, podendo haver ou não algum debate durante o julgamento em plenário.

Esse modelo decisório faz com que as decisões do Supremo Tribunal Federal sejam tomadas individualmente, ministro a ministro, com base em diferentes razões e argumentos, não tendo a decisão final uma racionalidade decisória uniforme. No entanto, é de se destacar que, quando se opta por uma corte colegiada, espera-se que as decisões sejam fruto de uma empreitada coletiva, na qual há não apenas a exposição individual das razões de cada um, mas uma troca de argumentos e razões para que, por meio desse processo deliberativo, chegue-se à melhor decisão. Essa dinâmica colegiada, deliberativa, só acontece se os membros do colegiado se engajarem, de fato, em uma honesta troca de argumentos, na qual todos se enxergam como colegas, e não como adversários. Assim, todos devem buscar de forma cooperativa a construção de uma decisão fundada em razões, erigida passo a passo, de forma coesa e coerente, sempre respeitando os votos divergentes fundados em um desacordo razoável (MENDES, 2013, p. 107-111).

Se o caso da Lei de Biossegurança estreou uma nova forma de condução de processos que envolvem questões que exigem a abertura do Supremo Tribunal Federal à sociedade e a outros campos do conhecimento, por outro lado, a forma tradicional de julgamento agregativo tem permanecido inalterada. O que se tem como resultado são decisões que, apesar de serem defensáveis e poderem ser consideradas acertadas, não se fundamentam em um raciocínio coerente e coeso, mas em uma pluralidade de razões e argumentos nem sempre lógicos ou ligados entre si. Têm prevalecido, assim, mais os saberes enciclopédicos e individuais de cada ministro do que a construção de uma decisão coletiva em favor de uma efetiva opinião da corte. Ou seja, o resultado final ainda é uma decisão meramente agregativa, tomada com base na soma dos dispositivos de cada voto (RODRIGUEZ, 2013, p. 79-80, 82-84). Nem mesmo a participação de terceiros, por intermédio dos amici curiae e dos convocados para a audiência pública, tem retirado dos julgamentos o caráter pessoal da decisão de cada um dos ministros. Vale dizer, a dinâmica decisória, ainda que aberta a participação de terceiros, segue sendo pessoal, opinativa, de tal forma que os ministros se comportam como indivíduos distantes que precisam ser convencidos, e não como membros e representantes de uma instituição cuja função é destrinçar o Direito, apresentar os melhores argumentos e, assim, solucionar os casos e justificar suas decisões racionalmente. As 
decisões continuam sendo individuais, e não construídas em função de um padrão argumentativo adequado ao caso (RODRIGUEZ, 2013, p. 76).

O que se conclui é que, da forma como o Supremo Tribunal Federal tem julgado os casos e se valido de audiências públicas e amici curiae, o potencial deliberativo da fase pré-decisional é reduzido pela restrição aos debates entre os expositores das audiências públicas e os amici curiae. A fase decisional, por sua vez, não possui um engajamento colegiado que encare as informações e os argumentos trazidos na fase anterior e permita a troca sincera de opiniões entre os ministros julgadores. Por fim, a fase pós-decisional carece de uma decisão deliberativa escrita que respeite ou corresponda aos pressupostos deliberativos anteriores. Como as decisões são individuais, cada ministro fundamenta sua decisão de uma maneira, de tal forma que não há uma opinião da Corte e tampouco uma uniformidade das decisões individuais entre si. Essa forma fracionária de se realizar o julgamento dos casos no Supremo Tribunal deixa claro como as decisões tomadas pelo Tribunal são fruto da mera soma aritmética dos dispositivos dos votos, e não das razões e dos argumentos apresentados ao longo do julgamento. Prevalece assim, exatamente, a dinâmica oposta à que se deseja para uma corte colegiada.

Diante disso, mais do que possibilitar a participação popular, é preciso que essa participação na fase pré-decisional seja levada a sério, que haja não apenas uma escuta dos intervenientes e convocados, mas que se promova um efetivo debate entre eles. É necessário que seus argumentos sejam levados em conta na hora da decisão, quer para compor o fundamento da decisão, quer para rejeitar os apontamentos realizados. Se essa participação popular passa a ser utilizada apenas como mais um passo para legitimar formalmente a decisão a ser exarada, perde-se o sentido da abertura dialógica do Supremo Tribunal Federal, esvaziam-se as inovações normativas e transforma-se um desejável diálogo em mera retórica formal de oitiva e participação.

Dessa forma, iniciativas como as audiências públicas realizadas até agora pelo Supremo Tribunal Federal, ainda que abertas ao reconhecimento de diversas vozes, terminam em instâncias típicas de um decisionismo judicial - a decisão isolada de cada ministro em seu gabinete (GARGARELLA, 2014, p. 148). Se, por um lado, as audiências públicas tiveram importância para as decisões dos ministros, por outro elas consistiram quase tão somente em uma esfera informativa, e não de debate e diálogo.

O principal problema dessas iniciativas dialógicas é que elas ainda têm sido demasiado atreladas à decisão discricionária do órgão judicial; decisão essa que vem, em geral, fundada sobre a ideia de supremacia judicial. Dessa maneira, não se pode dizer que o Supremo Tribunal Federal seja 
um tribunal dialógico. Ao contrário, é uma corte que se vale de instrumentos dialógicos (GARGARELLA, 2014, p. 149). A diferença é sutil, mas fundamental.

Há que se comemorar o primeiro passo - as iniciativas de abertura do Supremo Tribunal Federal à sociedade mediante a utilização de ferramentas de diálogo. No entanto, essas iniciativas devem ser avaliadas de forma bastante crítica (quando não cética) e exigente. Isso porque a abertura da Corte à participação dos outros Poderes, demais instituições públicas e privadas e, sobretudo, do povo, é ainda precária, pois não permite e nem realiza um efetivo debate e diálogo entre esses participantes e nem entre eles e o Supremo Tribunal Federal. Também é clara a carência de um engajamento colegiado no momento da decisão. E, além disso, falta, por fim, uma decisão deliberativa escrita, que encare os argumentos levantados na fase pré-decisional e que se fundamente nas razões e nos argumentos refinados que deveriam ter sido construídos durante a deliberação colegiada entre os ministros. Ou seja, ao fim e ao cabo, essas iniciativas não se constituem em efetivo diálogo interinstitucional e popular.

Desde uma perspectiva forte de democracia, não é necessário dizer que os (supostos) diálogos promovidos hoje pelo Supremo Tribunal Federal não se parecem com os diálogos exigidos por uma concepção deliberativa de democracia. É difícil considerar como diálogo uma situação na qual as partes envolvidas não apenas não se consideram em posição de igualdade, mas na qual uma das partes - juízes e cortes - se coloca em posição de dominação (GARGARELLA, 2014, p. 148).

Do ponto de vista de um debate público robusto e anterior à decisão, a performance deliberativa da fase pré-decisional pode e deve melhorar. Do ponto de vista da deliberação interna na fase decisional, falta um espaço ou momento que propicie o engajamento coletivo para uma deliberação sincera entre os ministros. As decisões fracionárias e individuais também não contribuem para um adequado momento pós-decisional, já que as decisões escritas individuais são muito pouco deliberativas, fundadas sobre diferentes razões e, assim, perde-se de vista a racionalidade decisória que fundamenta a decisão do Supremo Tribunal Federal. Mais do que isso, a forma atual como o Supremo Tribunal Federal decide, apesar de sua paulatina abertura, busca reafirmar a sua supremacia na definição do significado da Constituição. Ou seja, sua atuação tem se dado e sido por ele reafirmada dentro de um modelo de separação entre os Poderes que privilegia a disputa em vez de promover o diálogo entre as instituições, especialmente entre o Poder Judiciário e o Poder Legislativo. Dessa forma, essas aberturas aos diálogos tendem a ser pontuais, promovidas por agentes públicos bem intencionados, mas não ocorrem e tampouco se descrevem como práticas dialógicas efetivas, entre iguais (GARGARELLA, 2014, p. 146). 
Ao se exaltar e se exigir uma deliberação adequada das cortes se cumpre, assim, o compromisso com um constitucionalismo deliberativo e dialógico, no qual a legitimidade do exercício do controle judicial de constitucionalidade das leis para a definição do significado das normas constitucionais não decorre de uma suposta superioridade do Poder Judiciário, mas da qualidade deliberativa e argumentativa de suas decisões e do papel que assume perante os demais Poderes e instituições. Dessa forma, abre-se uma excelente possibilidade para que as cortes constitucionais sejam (ou se tornem), assim, instituições deliberativas exemplares. Essa qualidade, no entanto, não é presumida, precisa ser construída. É de se destacar também que, ao se defender uma performance deliberativa das cortes, não se está a insinuar uma suposta superioridade da deliberação judicial (geralmente fundada nas ideias do suposto isolamento entre o Poder Judiciário e a política, e de que decisões judiciais são baseadas em princípios e razões públicas) em relação à deliberação de qualquer outra instituição, mas sim a aprimorar e justificar o seu lugar em um sistema de tomada de decisão coletiva (MENDES, 2013, p. 102).

\section{CONSIDERAÇÕES FINAIS}

No que se refere ao Supremo Tribunal Federal, verificou-se, empiricamente, que a Corte tem se esforçado para se abrir a um diálogo antes de tomar suas decisões, especialmente por meio da realização de audiências públicas e mediante a admissão de amici curiae. Foi também possível verificar e concluir que tais instrumentos são importantes, porque, de fato, têm impacto e influência sobre as decisões dos ministros do Supremo Tribunal Federal. É de se destacar, entretanto, que os ministros, em suas decisões, têm se valido muito mais das informações e razões trazidas nas audiências públicas do que daquelas colacionadas pelos amici curiae. É possível concluir que o Supremo Tribunal Federal tem sido, assim, permeável à participação de pessoas e instituições que buscam colaborar com o momento decisório. A forma como o Supremo Tribunal Federal tem se valido da realização das audiências públicas e da admissão dos amici curiae, porém, tem sido muito pouco dialógica.

As audiências públicas têm se reduzido apenas à exposição de diferentes posições em relação a um dado caso e têm funcionado somente como espaço de complementação informativa dos ministros. Não se tem permitido o debate, o desafio e a troca de argumentos. Ademais, no atual modelo verifica-se que os ministros adotam uma participação eminentemente passiva, fazem poucas perguntas (muitas vezes nenhuma) e não se engajam no debate. 
A admissão ou recusa de amici curiae, por sua vez, precisa ser mais bem justificada pelo ministro relator. Cabe a ele possibilitar que mais vozes sejam ouvidas, sobretudo aquelas que têm poucas possibilidades de se fazerem audíveis. Sua decisão pela admissão ou rejeição dos amici curiae ganha, assim, especial relevância e exige uma fundamentação mais cuidadosa.

Além disso, para que haja um debate público efetivo e um diálogo genuíno, é preciso que o Supremo Tribunal Federal reconheça e promova o debate em todas as diferentes fases que envolvem o julgamento de um caso, notadamente a fase pré-decisional, a fase decisional e a fase pós-decisional.

Em que pesem a existência de instrumentos normativos destinados aos diálogos, a paulatina abertura do Supremo Tribunal Federal, a realização de audiências públicas e a admissão de amici curiae, as decisões exaradas pelo Supremo Tribunal Federal ainda têm sido tomadas de forma individual, sem um engajamento colegiado dos ministros e sem que o recurso às audiências públicas e aos amici curiae promovam um efetivo debate ou diálogo.

O Supremo Tribunal Federal não é, portanto, uma corte dialógica, mas um tribunal que se vale de instrumentos dialógicos. Sua atuação, assim, pode e deve ser aprimorada.

\section{REFERÊNCIAS}

BARROSO, Luís Roberto. O Novo Direito Constitucional Brasileiro: contribuições para a construção teórica e prática da jurisdição constitucional no Brasil. Belo Horizonte: Fórum, 2012.

GARGARELLA, Roberto. El nuevo constitucionalismo dialógico frente al sistema de los frenos y contrapesos. In: GARGARELLA, Roberto (Org.). Por una justicia dialógica: El Poder Judicial como promotor de la deliberación democrática. Buenos Aires: Siglo XXI, 2014.

MENDES, Conrado Hübner. Constitutional Courts and Deliberative Democracy. Oxford: Oxford University Press, 2013.

RAWLS, John. Political liberalism. New York: Columbia University Press, 1993.

RODRIGUEZ, José Rodrigo. Como decidem as cortes? Para uma crítica do Direito (brasileiro). Rio de Janeiro: Editora FGV, 2013.

VALLE, Vanice Regina Lírio do (Org.). Audiências Públicas e Ativismo: diálogo social no STF. Belo Horizonte: Fórum, 2012.WALDRON, Jeremy. Law and disagreement. Oxford: Clarendon Press, 1999. 


\title{
DO THE PUBLIC HEARINGS AND THE AMICI CURIAE INFLUENCE THE DECISIONS TAKEN BY THE BRAZILIAN SUPREME COURT? AND WHY IT SHOULD MATTER?
}

\begin{abstract}
This paper seeks to make a normative, empirical and critical analysis on how the Brazilian Supreme Court has been opening to society through amici curiae and public hearings. The goal here is to investigate the steps taken and the tools used by the Brazilian Supreme Court to be open to a dialogue with other branches, institutions and people (normative analysis); verify if the use of these tools have an effect on Justices' decisions (empirical analysis) and, finally, evaluate critically the results obtained (critical analysis).
\end{abstract}

KEYWORDS: Brazilian Supreme Court. Public hearings. Amicus Curiae.

Recebido: 9 agosto 2015

Aprovado: 21 outubro 2015 